\title{
BMJ Open Patient experience of treatment decision making for wet age-related macular degeneration disease: a qualitative study in China
}

Wei Bian, ${ }^{1,2}$ Junli Wan, ${ }^{1,2}$ Mingqiong Tan, ${ }^{1,2}$ Xiaoqing Wu, ${ }^{3}$ Jun Su, ${ }^{1,2}$ Lihua Wang ${ }^{4}$

To cite: Bian W, Wan J, Tan M, et al. Patient experience of treatment decision making for wet age-related macular degeneration disease: a qualitative study in China. BMJ Open 2019;9:e031020. doi:10.1136/ bmjopen-2019-031020

- Prepublication history and additional material for this paper are available online. To view these files, please visit the journal online ().

Received 11 April 2019 Revised 08 August 2019 Accepted 21 August 2019
D Check for updates

(c) Author(s) (or their employer(s)) 2019. Re-use permitted under CC BY-NC. No commercial re-use. See rights and permissions. Published by BMJ.

${ }^{1}$ Southwest Hospital/Southwest Eye Hospital, Third Military Medical University (Amy Medical University), Chongqing, China

${ }^{2}$ Key Lab of Visual Damage and Regeneration \& Restoration of Chongqing, Chongqing, China

${ }^{3}$ Outpatient Department of Southwest Hospital, Army Military Medical University, Chongqing, China

${ }^{4}$ Admin Office of Southwest Hospital, Army Medical University, Chongqing, China

Correspondence to

Lihua Wang;

3146183418@qq.com

\section{ABSTRACT}

Objectives This study aimed to investigate the experience of patients with wet age-related macular degeneration (wAMD) in treatment decision-making process.

Design A descriptive qualitative study was designed by using semistructured interviews, and the data analysis was conducted with the thematic analysis approach.

Participants and setting A convenient and purposive sample of 21 participants diagnosed with WAMD was recruited from May 2018 to September 2018. The study was conducted in the Eye Clinic of Southwest Hospital of Army Medical University in Chongqing located in the southwest of China.

Results The mean age of the participants was 64.48 years (ranging 50-81 years), and the duration of the disease ranged from 6 months to 48 months. Four major themes were identified from the original data analysis. These themes included facing the darkness (choosing from light and darkness and living in pain), constraints on decision making (doctor-oriented decision making, inadequacy of options and time), weighing alternatives (family influence, financial burden and maintaining social function) and decision-making support (professional decision-making assistance and peer support).

Conclusion This is a qualitative study attempting to explore the patient experience of treatment decision making for WAMD disease in China. Previous literature has focused on treatment effect and symptoms, rather than the individual experience and the wide contexts from a sociocultural perspective. Further studies, such as crosssectional studies, can be used to describe the status and determine the influencing factors of decision0making process, so as to develop an impact factor model of decision making and to formulate an intervention for patients with wAMD.

\section{INTRODUCTION}

Age-related macular degeneration (AMD) is the leading cause of irreversible visual impairment of degenerative fundus lesion in both developing and developed countries, affecting approximately 30000000 people worldwide and causing blindness of more than 500000 people. ${ }^{1}$ With the development of economy and medical care, the morbidity of AMD has been increasing year by year.
Strengths and limitations of this study

- This study attempted to explore the patient experience of treatment decision making for wet age-related macular degeneration disease in China with a qualitative method.

- The methodology generated four major themes that provide a deep understanding of the status and influencing factors of decision making, aiming to promote shared decision making.

- Participants were recruited from only one eye clinic in China and were not representative of all the patients with wAMD.

The wet age-related macular degeneration (wAMD) accounts for the most visual disability and causes severe sight loss. Recently, intravitreal injection of ranibizumab has become a treatment option, preventing further vision loss of $95 \%$ and improving sight of $40 \%$ of the patients. ${ }^{2}$ However, the patients are still suffering from visual impairment, mental disorders, family and social problems after getting the injection. ${ }^{3}$ Furthermore, some patients refuse to accept the injection, fearing side effects and high costs of continuous injections. ${ }^{4}$ Obviously, treatment decision making is so complicated for the patients with AMD and becomes a big problem of healthcare.

The decision-making process of the patients with AMD was influenced by several factors. First, the characteristics of the patients made important contributions to decision making. Passive patients tended to doctor-oriented decision making, while active patients preferred to taking an active part and making decisions on their own. ${ }^{56}$ However, age and gender did not play significant roles in influencing the decisions of the patients. ${ }^{7}$ Additionally, medical factors such as the professional ability of the doctors or optometrists can help the patients get more information about the treatment. ${ }^{8}$ The trust between 
the patients and the medical staff can help build a partnership and improve shared decision making (SDM). ${ }^{9}$ Besides, the treatment efficacy such as improvement of visual acuity was the prior thing to be considered by most of the patients with AMD, even though they might have to endure frequent intravitreal injections, long time of waiting for treatment and heavy economic and psychological burdens. ${ }^{10}$ Poor medical service that may result in slower service delivery and restrictions on management and guidance would cause difficulty in making decisions. ${ }^{11}$ Above all, most research on decision making of patients with AMD focused on the medical factors but seldom explored the difficulties and needs from the perspective of patients' actual experience.

SDM means that the medical staff and the patients work together to make a more reasonable and beneficial choice after the patients have been told about the effect, benefit and risk of the treatment and have fully expressed their views and values. ${ }^{12}$ With the development of SDM all over the world, the values and preferences of the patients are one of the most important factors for patient decision making. Therefore, deeply understanding the patient's perceptions and experiences in the decision-making process is beneficial to the more effective participation of the patients in clinical decision making, thus improving patient satisfaction and quality of life.

Qualitative research is a scientific method of observation to gather non-numerical data. The qualitative method is the best way to deeply understand human behaviour and research human experience. ${ }^{13}$ However, there are few qualitative studies to explore treatment decision-making process of patients with AMD. The main purpose of this study was to investigate the experience of patients with AMD in treatment decision-making process with face-toface interviews, so as to improve the quality of decision making and promote the SDM in ophthalmology.

\section{METHODS}

\section{Design and setting}

A descriptive qualitative study was designed to investigate the experience of treatment decision making for patients with AMD. Semistructured interviews have flexibility and were used to collect rich narrative data. ${ }^{13}$ This study was conducted in the Eye Clinic of Southwest Hospital of Army Medical University in Chongqing located in the southwest of China.

\section{Participants}

Purposive sampling was used to recruit patients from the Eye Clinic, and the recruitment stopped when the data were saturated. The inclusion criteria were as follows: (1) diagnosed with wAMD by the ophthalmologist; (2) more than 45 years old; (3) without any ophthalmic treatment therapies or surgeries such as glaucoma and cataract surgery; (4) without any other eye diseases or systematic diseases; (5) could read and understand Mandarin; and
(6) could understand and be willing to participate in the study.

\section{Data collection}

One-to-one semistructured interviews were administered to collect the information of the participants who met the inclusion criteria. The interview questions were originally devised based on the purpose of the study and the literature review and were then piloted after input from five patient advisors. Some unsuitable and ambiguous questions were discussed and revised by the expert panel (including one clinical medical professor, one expert in qualitative research methodology and two experts in nursing). The interviews were carried out by the first and the second authors with previous experience of qualitative research in eye care. All the patients were interviewed in a quiet room at the Eye Clinic, and each interview lasted approximately 30-60 min. Some examples of specific questions are listed as follows. 'How did you feel when you were diagnosed with AMD?', 'What kind of information on treatments did you get at that time?', 'Did you have enough time to ask and think about the information?', 'Was the decision about the treatment made by others or by yourself?', 'Do you feel that you were being supported by others during the decision-making process?' and 'Do you think that the final treatment decision was the result of taking full consideration of your values and preference?'. Data collection was finished after there were no new information could be obtained. Reflexivity is an acknowledgement of the role and influence of the researcher on the research project. ${ }^{14}$ To consider the reflexivity, reduce the research bias and ensure the confirmability of the research findings, a reflexive diary of the themes and an audit trail for the entire research process were performed by one of the researchers (JW).

\section{Data analysis}

The interviews were recorded by digital recorders and were transcribed verbatim. Reflective notes were used to keep the initial thoughts and ideas during transcription. The audio files were listened, and transcriptions were read several times for accuracy.

Data analysis was conducted with qualitative software analysis package NVivo 11.0 and by systematically adopting a thematic analysis approach. ${ }^{15}$ Thematic analysis is an approach to identifying, analysing and reporting themes or patterns within data. There are four phases in this analysis: (1) familiarising yourself with your data. This included repeated reading of the original data for meaning, patterns and so on. Notes or marked ideas were coded during this phase; (2) generating initial codes from the data; (3) searching for themes. This phase refocused on a broader level of themes, including categorising different codes into potential themes and sorting out all relevant encoding data from the identified subjects; and (4) reviewing themes. All the collated extracts for each theme should be read and considered, making sure they could form a coherent pattern. The 
analysis was conducted by JW, and the themes reviewed by WB and LW. To make sure the accuracy and rigour, all the members of the research group had regular meetings to discuss and modify the codes. Besides, all the themes extracted from the data were rechecked by the expert panel. Patients made significant contributions to reflection on the meaning and interpretation of the interview data.

\section{Patient and public involvement}

No patient or public were involved in the design, recruitment or conduct of the study. All the patients will be informed via email or telephone call about the publication of the results.

\section{Ethics approval}

Informed written consent relating to the study was obtained from each participant before participation in the study. All the participants were reassured that their treatment and care would not be affected even if they did not take part in the study. Our studies were conducted in accordance with the Declaration of Helsinki.

\section{RESULTS}

\section{Participant characteristics}

Twenty-one participants diagnosed with AMD were recruited from May 2018 to September 2018. Participants ranged from 50 to 81 years old (mean age of 64.48 years), having a diagnosis of AMD with the mean disease duration of 20.43 months (range: 6 months -48 months). The detailed characteristics of the participants are shown in table 1 . The time of interviews ranged from $30 \mathrm{~min}$ to 55 $\min$.

\section{Themes}

Four themes were identified after the analysis of the original data. These themes included facing the darkness, constraints on decision making, weighing alternatives and decision-making support. The domains of the four themes are presented in detail in figure 1, and more quotations from participants are presented in online supplementary table 1.

\section{Facing the darkness}

\section{Choosing from light and darkness}

Most patients cannot accept blindness of their eyes and did not want to live in the dark forever. They believed that the disease was an opportunity to re-evaluate their life and establish new priorities through their new lives, and therefore they should get the treatment and stick to it.

I have to get the treatment. I don't want to live in darkness. I deserve a better life.

However, a small number of older patients thought it was natural to have a worse and worse vision when they grew older. They accepted the terminal nature of the disease and did not want to make any changes to their lifestyle, thus gradually progressing towards darkness.

\begin{tabular}{|c|c|c|c|c|}
\hline No. & Gender & $\begin{array}{l}\text { Age } \\
\text { (years) }\end{array}$ & $\begin{array}{l}\text { Eye affected } \\
\text { by AMD }\end{array}$ & $\begin{array}{l}\text { Duration of } \\
\text { diseases }\end{array}$ \\
\hline 1 & Female & 81 & Bilateral & 12 months \\
\hline 2 & Male & 62 & Bilateral & 24 months \\
\hline 3 & Female & 72 & Bilateral & 6 months \\
\hline 4 & Male & 77 & Bilateral & 24 months \\
\hline 5 & Female & 51 & Unilateral & 18 months \\
\hline 6 & Male & 50 & Unilateral & 13 months \\
\hline 7 & Female & 53 & Unilateral & 10 months \\
\hline 8 & Female & 69 & Bilateral & 18 months \\
\hline 9 & Female & 70 & Unilateral & 10 months \\
\hline 10 & Female & 68 & Bilateral & 9 months \\
\hline 11 & Female & 65 & Bilateral & 22 months \\
\hline 12 & Female & 54 & Unilateral & 16 months \\
\hline 13 & Female & 51 & Bilateral & 36 months \\
\hline 14 & Male & 61 & Bilateral & 32 months \\
\hline 15 & Female & 63 & Unilateral & 28 months \\
\hline 16 & Female & 66 & Unilateral & 48 months \\
\hline 17 & Female & 64 & Bilateral & 18 months \\
\hline 18 & Female & 74 & Unilateral & 24 months \\
\hline 19 & Female & 78 & Bilateral & 38 months \\
\hline 20 & Female & 63 & Unilateral & 6 months \\
\hline 21 & Male & 62 & Unilateral & 17 months \\
\hline
\end{tabular}

$\mathrm{AMD}$, age-related macular degeneration.

I think this is a natural process. I'm getting older. My children have already grown up and do not need to be taken care of anymore. I'll stay at home, being blind.

\section{Living in pain}

Some patients were not sure about how many injections they would have to take and how much vision they would regain. They were fearful of the future and lived on the brink of pain because of the unpredictability of prognosis, which made them reconsider whether they should continue the injections.

I asked doctors what would happen to my eyes in the future, but they could not be sure whether my vision would go worse and become blind eventually. I am afraid about the future. I don't know anything about it.

\section{Constraints on decision making}

\section{Doctor-oriented decision making}

Half of the patients believed that doctors can make the right decision with authority, particularly when the rationale was explained to them, so they tended to let the doctors make the choice for them even if their involvement in treatment decision making was limited. 


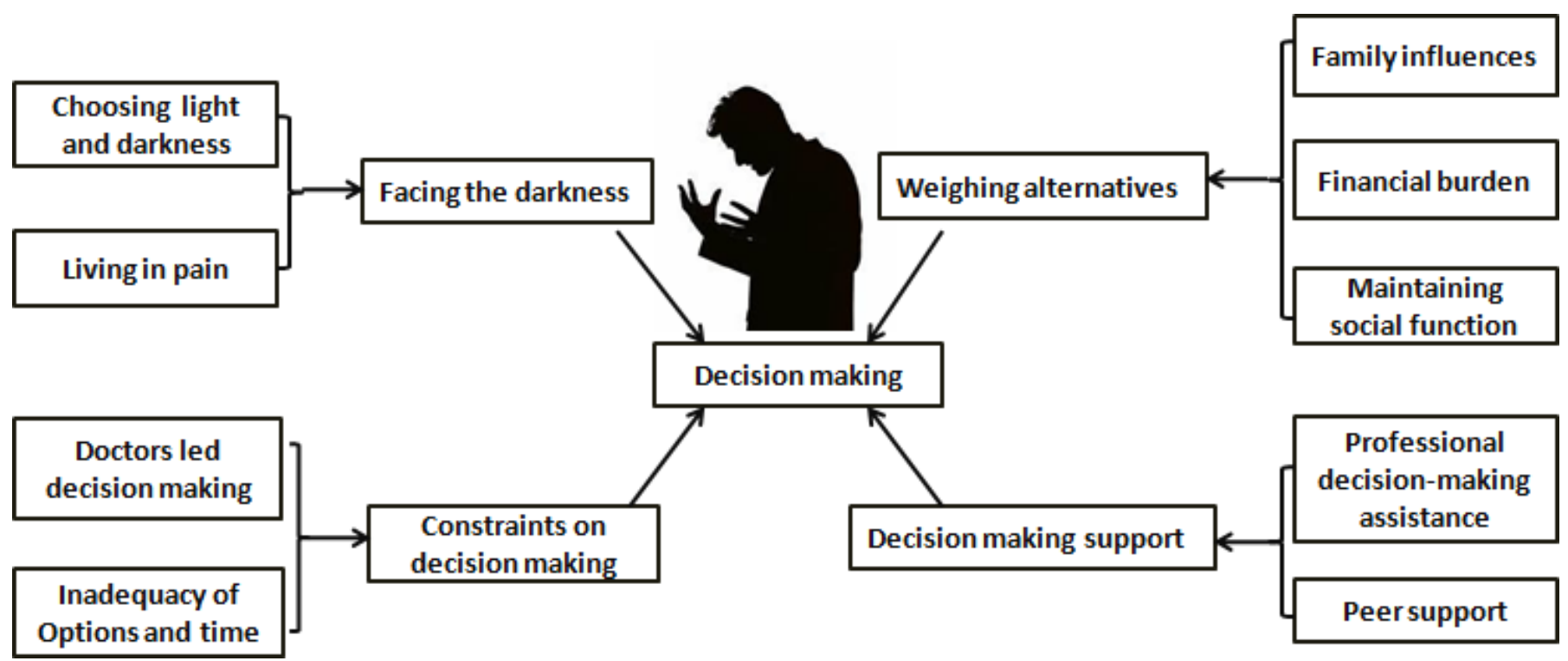

Figure 1 Domains in decision-making process of patients with age-related macular degeneration

Doctors are experts on the treatment. We trust them, of course, and it is the right thing to follow their suggestions.

\section{Inadequacy of options and time}

Most patients pointed out that doctors provided only one treatment decision without telling other available treatment options and the consequences of not accepting treatment. They concerned about the lack of knowledge of the different options.

The doctor told me that intravitreal injection of anti-neovascularization drugs is the best way to treat AMD and I must be treated as soon as possible. I am a little confused about whether it is the best option.

Some patients thought they did not have enough time to give careful consideration to the treatment and had to make decisions in a hurry.

The doctor talked a lot, but I didn't fully understand the information. I needed more time to digest the information and to consider whether my decision was correct.

\section{Weighing alternatives \\ Family influences}

The family had a great influence on patients' decision making in the treatment. Some patients were afraid that continuous injections and examinations would be a burden to the family and made troubles to their life and work.

The doctor said that this injection could be more than once, and I don't want to be a burden to the family. You do not know what it means to me getting the injection once in one or 2 months. My relatives have to spend more time to take care of me, and I have to consider their feelings.

\section{Financial burden}

At present, AMD is mainly treated by intravitreal injection of antineovascularisation drugs for many times. However, the high cost of the treatment will bring a great economic pressure to some patients and their families.

The injection is too expensive, and it is such a big burden to a common person with average salary.

\section{Maintaining social function}

For most patients, whether the normal daily life, family responsibilities and social roles could be maintained during the treatment was the main factor to be considered. They hoped that the treatment could improve the vision of their eyes and had less influence on their lifestyle and quality of life.

My first reaction was that I had to work. If I cannot, what should I do? What about my family?

I am in charge of my family work, and take care of my wife and children. Frequent examinations and injections might lead to inadequate time for taking care of my family.

\section{Decision-making support}

\section{Professional decision-making assistance}

Providing professional knowledge is always the most important and direct approach to the medical information obtainment for the patients. Most patients hoped that doctors can provide enough professional knowledge of their treatment, so they could have enough information to make reasonable decisions.

The doctor only told me that the disease can be treated by injection, but did not tell me any side effects of the treatment. We need more detailed information about what to do after the operation. Maybe the doctors are too busy. 
A few patients expected that some decision-making aids or intelligent information tools for patients could be provided to assist them in decision making.

We still hope that there could be a patient decision-making aid explaining all kinds of treatment plans in detail, so we can get more information and make the right decisions.

\section{Peer support}

The experience of other patients greatly influenced the patients' decision making. Communication with other patients and sharing the treatment experiences can help the patients understand the treatment and make the right decisions.

I like chatting with other patients for obtaining information. For example, I may know which kind of treatment is better, whether the treatments have adverse reactions or not, and so on. I can learn from their experience and try to make my own decision.

\section{DISCUSSION}

This is a research using a qualitative study conducted in China to explore the patient experience of treatment decision making for wAMD disease. The four major themes identified from the data were: (1) facing the darkness; (2) constraints on decision making; (3) weighing alternatives; and (4) decision making support.

For most patients in our study, choosing the treatment means choosing light. Therefore, as long as the vision is improved, they can sustain all the inconvenience caused and stick to the treatment. However, they concerned about the effectiveness of the treatment and were afraid that the treatment would only last for a while. The uncertainty about the future made them cautious about the improvements and left them in anxiety and pain, which is consistent with the previous literature. ${ }^{16-18}$ In the previous literature, patients highlighted fears about the potential deterioration of the vision, loss of sight in the future, side effects and lengthy, frequent and repeated visits caused by the treatment that are even stressful for them. Therefore, understanding patients' perceptions of the treatment and encouraging them to clarify their concerns are important steps to understand the decision motivation of the patients.

Patient participation in decision making fulfils the ethical principle of patient autonomy and is also the key element of the SDM. ${ }^{19}$ However, we found that more than half of the patients with AMD preferred to leave the final decision up to their doctors and played passive roles in treatment decision making. This fact about patients with AMD was different from patients with other diseases such as fractures ${ }^{20}$ or cancers ${ }^{21}{ }^{22}$ who were willing to make decisions on their own. The main reason may be that most of the patients with AMD were older people who were limited by their physical, psychological and social functions. They are more likely to express the desire as more passive roles in decision making. ${ }^{23}$ Therefore, a personalised mode of patient-participated decision making should be established according to the patient's willingness to meet the needs and stimulate the subjective initiative of the patients. ${ }^{24}$ Additionally, in our research, most patients were not provided with adequate treatment information, including potential options, procedures of the injection and side effects, from the doctors or professional organisation. This finding was different from Senra's study in which most patients were satisfied with the support and information of the condition and treatment from the hospital. ${ }^{18}$ This difference may be due to the larger number of outpatient visits that may lead to little time with the patients and the lack of professional organisations in China compared with the developed countries that have established professional institutions and mechanisms such as service delivery. ${ }^{25}{ }^{26}$ Consequently, more time to stay with the patients and provide comprehensive information about treatment options as well as the advantages and disadvantages of each treatment for patients should be encouraged in the hospital. Also, sufficient time should be given to the patients so that they could have a careful consideration and make their best clinical decision to meet their own needs.

Family members play an important role in the treatment process of the patients, especially in the Chinese cultural context. As the physical functions of patients declined because of the visual dysfunction, the family members would become the main source fulfilling their physical functions and providing emotional and social support. Family members also participated into the vision rehabilitation of the patients, which had an important impact on the health status and rehabilitation results of the patients. ${ }^{27}$ Therefore, family members influenced the decision making of the patients and might even directly make decisions for the patients. In this study, we also found that the most important issue that was weighed by almost all patients in decision making was the impact on family, which was also reported by other studies. ${ }^{28}{ }^{29}$ Patients would worry about that the decision would bring a significant burden to the family and change their lifestyles, and families' opinions on treatment would directly affect patient decision making. Therefore, making good use of the family role and encouraging the family to provide support for the patients were one of the most important steps to improve SDM. Furthermore, the financial burden was an important factor influencing treatment options that are rarely found in studies in developed countries that had advanced medical guarantee. The AMD is mainly treated by intravitreal injection of antineovascularisation drugs for many times, and the cost is very expensive. Since China's current medical insurance system fails to meet the growing demand for medical services, many patients may choose a more conservative and less expensive treatment option due to economic pressures. Therefore, how to reduce the medical burden of patients with AMD is the goal and the focus of the further deepened reform. 
We also found that maintaining social function was also an important consideration in patient decision making and was even more important than the effect caused by the injection. Therefore, when the social lives of the patients were seriously interfered by the treatment, the decision-making skills should be comprehensively evaluated, and the risk communication of the decision making should be conducted. The decision should be made by the patients after they were clear about their personal opinions, preferences, values and priorities, which aimed to promote the self-efficacy and self-management of the patients. $^{30}$

In our study, most patients recognised the expertise of medical staff to be the most important part of patient decision support. Reliable and effective information support for decision making can develop appropriate expectations of the patients and reduce their uneasiness, confusion and fear resulting from lack of information, so that patients can more actively participate in the diagnosis and treatment as well as self-management of the disease. ${ }^{31}$ Furthermore, modern medical instruments including patient decision aids (PDAs) were also advocated to solve decision conflict and promote SDM. PDAs can be used to show the advantages and disadvantages of different options, to help patients understand their values and preferences and to make the most suitable decision after discussion with the medical staff. ${ }^{32}$ Although PDAs for cataract surgery, ${ }^{33}$ primary open-angle glaucoma ${ }^{34}$ and nutrition advice for $\mathrm{AMD}^{35}$ have been developed and used in some foreign counties, there was no PDA available in the field of ophthalmological medicine in China. Therefore, how to normatively introduce foreign decision-making aids from other countries and scientifically develop our own PDAs was a very important and urgent problem to deal with in the near future. Another important finding was that patients were significantly influenced by the other patients' experience that is even more influential than the suggestion from the doctors, which was consistent with other studies. ${ }^{36}{ }^{37}$ Interventions based on peer support could be a persuasive and powerful way to help patients acquire more disease-related knowledge, alleviate their anxiety and depression and reassess the impact of disease on family life and social functions, which could help them find the most suitable option of the treatment. ${ }^{38}$

There are a few limitations to our study. For geographical convenience, participants were recruited from only one eye clinic in China. Some of the issues may be specific to this enrolled clinic and were not representative of all the patients with AMD. However, we achieved data saturation and showed a good picture of how Chinese patients with AMD experienced in the treatment decision-making process. Further studies should be conducted in other eye clinics to test and supplement these results. Furthermore, the patients in this study were acquainted with the researchers, suggesting that patients might be unwilling to speak out their inner thoughts and worry about the confidentiality of their information. However, trust was built before the interview, and general questions were asked at the beginning to ease the patients and make them get more used to the interview.

\section{Implication of the study}

Several strategies to improve patient decision making described in this qualitative study could be considered and implemented immediately. First, it will formally incorporate peers with AMD (other patients) into the new patient group as instructors or educators, which is beneficial. Furthermore, the current shared decision-making model based on the doctor-nurse-patient tripartite group should be revised to the doctor-nursepatient-family model in the Chinese context, which is more suitable in China. Second, the scientific introduction of PDAs and establishment of standard application models will improve the SDM. Besides, standard training courses should be established for the medical staff and patients to make good use of the PDAs. Third, the clinical practice guidelines for education about treatment options of AMD should be modified and contain more details about the duration time, contents and methods of the education.

\section{CONCLUSION}

This is a qualitative study to explore the patient experience of treatment decision making for wAMD disease in China. Previous literature has focused on treatment effect and symptoms, rather than the individual experience and the wide contexts from a sociocultural perspective. Our findings illuminated the significance of understanding the patients' perceptions of the treatments, such as 'choosing from light and darkness' and 'living in pain'. We also pointed out that the constraints on decision making resulted from inadequacy of decision options and time and that patient participation into the decision making should be evaluated according to their own willingness. In this study, we also highlighted the necessity of enhancing the connection and communication between the medical staff and patients in order to provide patients with more scientific and comprehensive information and advocated peer influence on disease management of patients. Further studies, such as cross-sectional studies, can be performed to describe the status and determine the influencing factors of decision-making process, which will help develop an impact factor model of decision making and formulate an intervention for patients with AMD.

Acknowledgements Special thanks to the participants who volunteered to take part in this research. The authors would also like to thank Miss Jia Wang for help in modifying the language of this manuscript.

Contributors WB, JW and LW were responsible for the conception and design of the study and compiling the interview schedule. WB, JW, XW and MT were responsible for acquisition of data. WB and JW were responsible for the analysis of the study and interpretation of data. WB and JW drafted the article. WB, JW, XW, JS and MT revised the article critically for important intellectual content. All authors have read and approved the final manuscript. 
Funding This study was funded by the Chongqing Technology Innovation and Application Demonstration (Social and Livelihood General) Project (cstc2018jscxmsybX0129), Chongqing Social Science Planning Youth Project (2018QNSH42) and Chongqing Postgraduate Education and Teaching Reform Project (yjg172013).

Competing interests None declared.

Patient consent for publication Not required.

Ethics approval Ethics Committee of the First Affiliated Hospital of Army Military Medical University, PLA (Ethics Reference KY201862).

Provenance and peer review Not commissioned; externally peer reviewed.

Data availability statement All data relevant to the study are included in the article or uploaded as supplementary information.

Open access This is an open access article distributed in accordance with the Creative Commons Attribution Non Commercial (CC BY-NC 4.0) license, which permits others to distribute, remix, adapt, build upon this work non-commercially, and license their derivative works on different terms, provided the original work is properly cited, appropriate credit is given, any changes made indicated, and the use is non-commercial. See: http://creativecommons.org/licenses/by-nc/4.0/.

\section{REFERENCES}

1. Fisher DE, Jonasson F, Eiriksdottir G, et al. Age-Related macular degeneration and mortality in community-dwelling elders: the age, gene/environment susceptibility Reykjavik study. Ophthalmology 2015;122:382-90.

2. Mitchell P, Liew G, Gopinath B, et al. Age-Related macular degeneration. The Lancet 2018;392:1147-59.

3. Brown DM, Kaiser PK, Michels M, et al. Ranibizumab versus verteporfin for neovascular age-related macular degeneration. $N$ Eng J Med Overseas Ed 2006;355:1432-44.

4. Bian W, Wan J, Smith G, et al. Domains of health-related quality of life in age-related macular degeneration: a qualitative study in the Chinese cultural context. BMJ Open 2018;8:e018756.

5. Danner M, Vennedey V, Hiligsmann M, et al. Comparing analytic hierarchy process and Discrete-Choice experiment to elicit patient preferences for treatment characteristics in age-related macular degeneration. Value in Health 2017;20:1166-73.

6. Mestre AG. Autonomy of the patient with chronic diseases: from passive patient to active patient. Enfermería Clínica 2014;24:67-73.

7. Bernstein PS, Seddon JM. Decision-making in the treatment of subfoveal neovascularization in age-related macular degeneration. An analysis from the patient's perspective. Retina 1996;16:112-6.

8. Reeves BC, Scott LJ, Taylor J, et al. Effectiveness of community versus Hospital eye service follow-up for patients with neovascular age-related macular degeneration with quiescent disease (echoes): a virtual non-inferiority trial. BMJ Open 2016;6:e010685.

9. Emsfors Åsa, Christensson L, Elgán C. Nursing actions that create a sense of good nursing care in patients with wet age-related macular degeneration. J Clin Nurs 2017;26:2680-8.

10. Mueller S, Agostini H, Ehlken C, et al. Patient preferences in the treatment of neovascular age-related macular degeneration: a discrete choice experiment. Ophthalmology 2016;123:876.

11. Harding SP. Neovascular age-related macular degeneration: decision making and optimal management. Eye 2010;24:497-505.

12. Spatz ES, Krumholz HM, Moulton BW. Prime time for shared decision making. JAMA 2017;317.

13. Pope C, Ziebland S, Mays N. Qualitative research in health care. Analysing qualitative data. BMJ 2000;320:114-6.

14. Janzen KJ. Into the depths of reflexivity and back Again-When research mirrors personal experience: a personal journey into the spaces of liminality. Qualitative Report 2016;21.

15. Buetow $\mathrm{S}$. Thematic analysis and its reconceptualization as 'saliency analysis'. J Health Serv Res Policy 2010;15:123-5.
16. Boyle J, Vukicevic M, Koklanis K, et al. Experiences of patients undergoing anti-VEGF treatment for neovascular age-related macular degeneration: a systematic review. Psychol Health Med 2015;20:296-310.

17. McCloud C, Khadka J, Gilhotra JS, et al. Divergence in the lived experience of people with macular degeneration. Optom Vis Sci 2014:91:966-74.

18. Senra H, Balaskas $\mathrm{K}$, Mahmoodi N, et al. Experience of anti-VEGF treatment and clinical levels of depression and anxiety in patients with wet age-related macular degeneration. Am J Ophthalmol 2017; 177:213-24.

19. Fraenkel L, McGraw S. Participation in medical decision making: the patients' perspective. Med Decis Making 2007;27:533-8.

20. Gong HS, Huh JK, Lee JH, et al. Patients' preferred and retrospectively perceived levels of involvement during decisionmaking regarding carpal tunnel release. J Bone Joint Surg Am 2011;93:1527-33.

21. Hubbard G, Kidd L, Donaghy E. Preferences for involvement in treatment decision making of patients with cancer: a review of the literature. Eur J Oncol Nurs 2008;12:299-318.

22. Hirpara DH, Cleghorn MC, Sockalingam S, et al. Understanding the complexities of shared decision-making in cancer: a qualitative study of the perspectives of patients undergoing colorectal surgery. Can J Surg 2016;59:197-204.

23. Tak HJ, Ruhnke GW, Meltzer DO. Association of patient preferences for participation in decision making with length of stay and costs among hospitalized patients. JAMA Intern Med 2013;173:1195-203.

24. Ekdahl AW, Andersson L, Wiréhn A-B, et al. Are elderly people with co-morbidities involved adequately in medical decision making when hospitalised? A cross-sectional survey. BMC Geriatr 2011;11:46.

25. Yasmin S. An integrated low vision service: Sri Lanka. Community Eye Health 2012;25.

26. Jackson ML. Vision rehabilitation for Canadians with less than $20 / 40$ acuity: the SmartSight model. Can J Ophthalmol 2006;41:355-61.

27. Bambara JK, Wadley V, Owsley C, et al. Family functioning and low vision: a systematic review. J Vis Impair Blind 2009;103:137-49.

28. Moore LW, Constantino RE, Allen M. Severe visual impairment in older women. West J Nurs Res 2000;22:571-95.

29. Feely M, Vetere A, Myers LB. A qualitative analysis of reading rehabilitation of persons with age-related macular degeneration. $J$ Vis Impair Blind 2007;101:44-50.

30. Clark NM, Nelson BW, Valerio MA, et al. Consideration of Shared Decision Making in Nursing: A Review of Clinicians' Perceptions and Interventions. Open Nurs J 2009;3:65-75.

31. Joseph-Williams N, Elwyn G, Edwards A. Knowledge is not power for patients: a systematic review and thematic synthesis of patientreported barriers and facilitators to shared decision making. Patient Educ Couns 2014;94:291-309.

32. O'Connor AM, Stacey D, Entwistle V, et al. Decision AIDS for people facing health treatment or screening decisions. Cochrane Database Syst Rev 2003;(2):CD001431.

33. Swanson MW. Medical decision-making capacity and cataract surgery. Optom Vis Sci 2012;89:e23-6.

34. Shum JWH, Lam WWT, Choy BNK, et al. Development and pilottesting of patient decision aid for use among Chinese patients with primary open-angle glaucoma. BMJ Open Ophthalmology 2017;2:e000100. Lai JSM.

35. Stevens R, Bartlett H, Cooke R. Evaluation of a clinical decisionmaking aid for nutrition advice in age-related macular degeneration. Br J Vis Impair 2017;35:185-96.

36. Bradley P, Mitchell J, Bradley C. Peer support for people newly diagnosed with macular degeneration: a pilot study. Int Congr Ser 2005;1282:211-5.

37. Lee A, Gudex C, Povlsen JV, et al. Patients' views regarding choice of dialysis modality. Nephrology Dialysis Transplantation 2008;23:3953-9.

38. Tollow P, Williams VS, Harcourt D, et al. "It felt like unfinished business, it feels like that's finished now": Women's experiences of decision making around contralateral prophylactic mastectomy (CPM). Psychooncology 2019;28:1328-34. 